\title{
AIAA 2002-0230
}

\section{Thrust Augmentation with Mixer/Ejector Systems}

W. Presz, Jr.

Western New England College

Springfield, MA

G. Reynolds

Stage III Technologies

LaJolla, CA

C. Hunter

NASA Langley

Hampton, VA

\section{0th AIAA Aerospace Sciences Meeting \& Exhibit 14-17 January 2002 / Reno, NV}

For permission to copy or to republish, contact the copyright owner named on the first page. For AIAA-held copyright, write to AIAA Permissions Department, 1801 Alexander Bell Drive, Suite 500, Reston, VA, 20191-4344. 


\title{
THRUST AUGMENTATION WITH MIXER/EJECTOR SYSTEMS
}

\author{
by
}

Dr. Walter M. Presz, Jr.

Western New England College

Springfield, MA

Gary Reynolds

Stage III Technologies

LaJolla, CA

Dr. Craig Hunter

NASA Langley Research Center

Hampton, VA

\begin{abstract}
$\underline{\text { Abstract }}$
Older commercial aircraft often exceed FAA sideline noise regulations. The major problem is the jet noise associated with the high exhaust velocities of the low bypass ratio engines on such aircraft. Mixer/ejector exhaust systems can provide a simple means of reducing the jet noise on these aircraft by mixing cool ambient air with the high velocity engine gases before they are exhausted to ambient. This paper presents new information on thrust performance predictions, and thrust augmentation capabilities of mixer/ejectors. Results are presented from the recent development program of the patented Alternating Lobe Mixer Ejector Concept (ALMEC) suppressor system for the Gulfstream GII, GIIB and GIII aircraft. Mixer/ejector performance procedures are presented which include classical control volume analyses, compound compressible flow theory, lobed nozzle loss correlations and state of the art computational fluid dynamic predictions. The mixer/ejector thrust predictions are compared to subscale wind tunnel test model data and actual aircraft flight test measurements. The results demonstrate that a properly designed mixer/ejector noise suppressor can increase effective engine bypass ratio and generate large thrust gains at takeoff conditions with little or no thrust loss at cruise conditions. The cruise performance obtained for such noise suppressor systems is shown to be a strong function of installation effects on the aircraft.
\end{abstract}

\section{Nomenclature}

\section{$\underline{\text { Symbol }}$}

\section{$\mathrm{A}=$ Area}

C.V. $=$ Control Volume

$\dot{\mathrm{m}}=$ Mass flow rate

$\mathrm{P}=$ Pressure

$$
\begin{aligned}
& M=\text { Mach Number } \\
& T=\text { Temperature } \\
& T h=\text { Thrust } \\
& V=\text { Velocity } \\
& \phi=\text { Thrust Augmentation, } \frac{T h}{\dot{m}_{p} V_{p}} . \\
& \rho=\text { Density }
\end{aligned}
$$

\section{Subscript}

$$
\begin{aligned}
& a, A=\text { Airplane } \\
& a m b=\text { Ambient Conditions } \\
& e=\text { System Exit Station } \\
& \mathrm{p}=\text { Primary Stream } \\
& \mathrm{s}=\text { Secondary Stream } \\
& \mathrm{t}=\text { Stagnation Conditions } \\
& 1=\text { Primary Nozzle Exit } \\
& 2=\text { Ejector Shroud Exit }
\end{aligned}
$$

\section{Introduction}

Jet engines generate thrust by expanding a fluid with higher than ambient pressure through an exhaust nozzle to ambient pressure. The thrust generated is proportional to the mass flow times the fluid exhaust velocity. The energy needed to generate the thrust is proportional to the mass flow times the square of the fluid exhaust velocity. Therefore, considerable exhaust flow energy is expended while generating thrust. Transferring more of the primary flow energy to some of the ambient fluid before exhausting the flow through exhaust nozzles can increase the thrust efficiency of such systems. Such energy transfer for thrust augmentation can occur 
through pressure forces, or through viscous forces. A turbine and fan combination uses pressure forces to transfer energy from the primary flow to the secondary stream passing through the fan. Such an energy transfer, ideally, would be isentropic. Heiser (Reference 1) refers to such an isentropic device as an ideal augmentor. An ejector, on the other hand, uses viscous forces to pump a secondary fluid. An ejector is a pump with

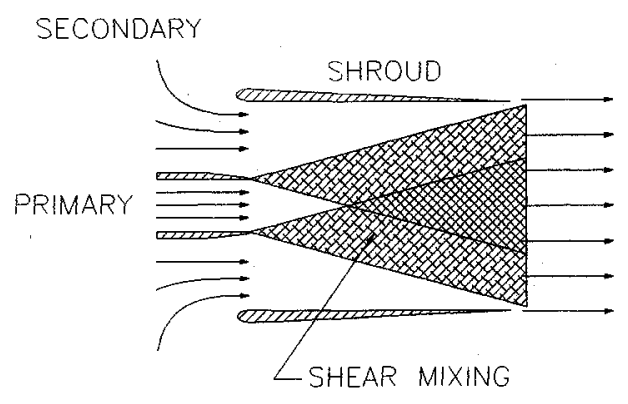

Figure 1 - Ejector Schematic

no moving parts. Figure 1 is a schematic of an ejector. The key components include a primary nozzle and a mixing duct, or shroud as shown. Shear, or viscous forces generated in the mixing region of the primary jet, transfer flow energy from the primary fluid to the secondary fluid. Ideally, the flow exiting the mixing duct will be uniform. The problem with such ejector systems is the slow rate of viscous mixing.

Figure 2 presents a schematic of a mixer/ejector exhaust suppressor. A primary lobed nozzle is incorporated into this ejector system. The lobed nozzle generates streamwise vorticity that enhances the flow mixing, increases secondary flow pumping, and dramatically decreases the ejector mixing length required for optimum performance (References 2 through 6). Ideally, the lower velocity-higher mass flow rate of the mixer/ejector exhaust will provide static thrust gain while reducing take off jet noise (sideline noise). Sideline noise is one of the three components required by the FAA and is measured "at the point, on a line parallel to and 1476 feet $(450$ meters) from the extended centerline of the runway where the noise level after liftoff is greatest" (FAR Part 36). The major component of sideline noise is jet noise. Jet noise is associated with the high exhaust velocities of jet engines.

Thus, a mixer/ejector exhaust suppressor has the potential to reduce the sideline noise on older jet aircraft while increasing the static thrust of the aircraft engines. The static thrust augmentation is primarily a result of inlet lip suction on the ejector mixing shroud caused by the secondary flow acceleration around the ejector inlet lip as shown in Figure 3 (Reference 7). Figure 3 schematically presents the flow

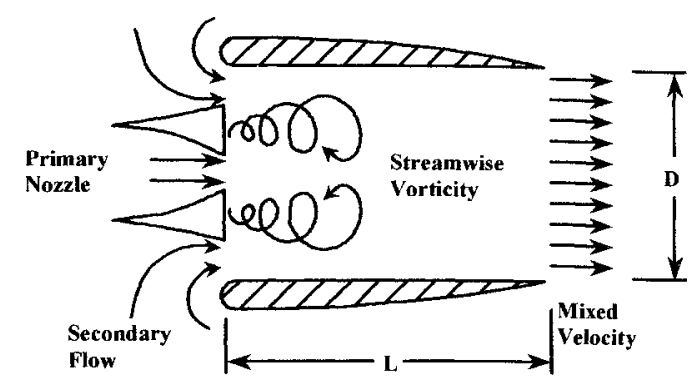

Figure 2 - Mixer/Ejector Schematic

streamlines of an ejector at different airplane flight speeds. Such ejector systems generate thrust gains when stationary. The same system however, may generate significant thrust losses at cruise conditions. With forward flight, the secondary flow is no longer accelerated around the inlet lip as shown schematically in Figure 3. This secondary flow change causes a rapid drop off in the ejector lip suction, and results in a thrust loss at cruise conditions.
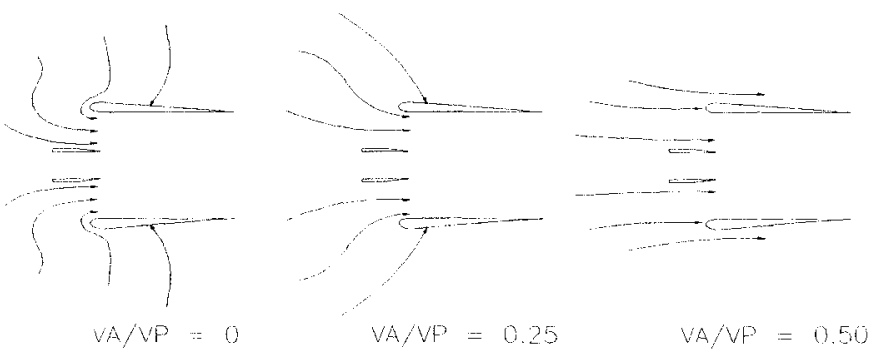

Figure 3 - Ejector Flow Streamlines

This paper presents new information on performance predictions and thrust measurements of mixer/ejectors. Results are presented from the recent development program of the patented Alternating Lobe Mixer Ejector Concept (ALMEC) suppressor system for the Gulfstream GII, GIIB and GIII aircraft (Reference 8). Figure 4 presents a photograph of the Gulfstream aircraft showing the engine installation studied. Two Rolls Royce Spey 511-8 engines are pylon mounted on the fuselage of this aircraft. Figure 5 presents a schematic of the proposed mixer/ejector exhaust suppressor for the Gulfstream aircraft; the ALMEC system. The suppressor has two major components; the engine tailpipe (i.e. which includes the lobed nozzle), and the ejector shroud. The engine nozzle has ten lobes designed to efficiently, and rapidly, mix the engine flow with ejector secondary air. Five of the lobes are shallow. The other five lobes are much longer, and are designed to penetrate deeply into the hot engine jet core. The shallow and deep lobes alternate around the circumference of the nozzle. The alternating lobes are required to allow deep 


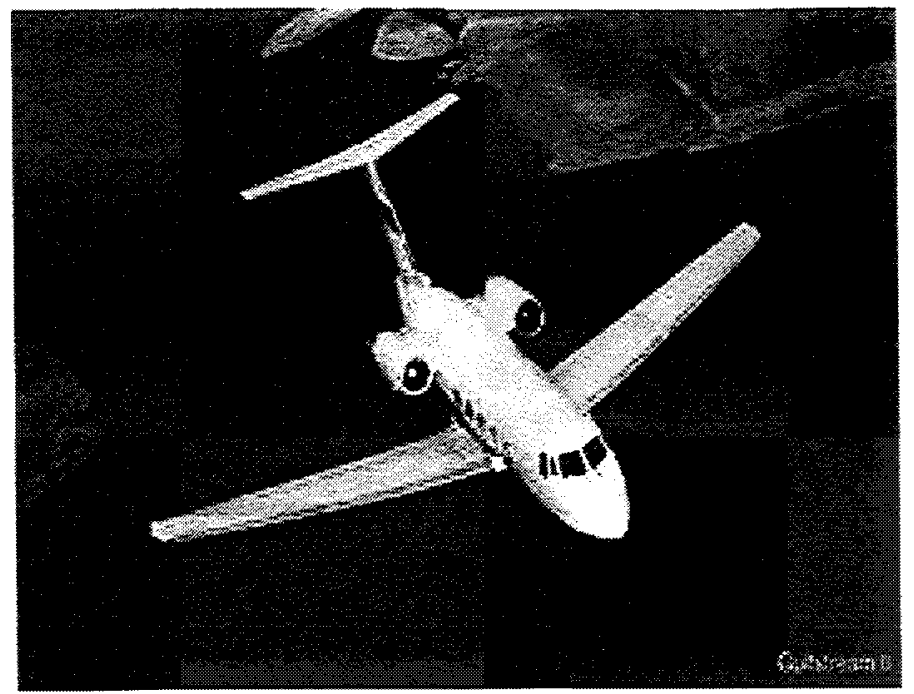

Figure 4 - Gulfstream GII Aircraft

penetration of the jet core, without setting up large flow losses due to flow channeling. The alternating lobes also set up separate axial vorticity patterns that interact with each other to enhance mixing. The ejector shroud has a length to diameter ratio of about one. This provides good mixing without large wall friction losses and large weights. The ratio of the shroud area to the nozzle exit area is about two. This area ratio was chosen to provide the necessary secondary flow pumping at static and takeoff conditions, but minimizes the cruise drag losses associated with the ejector secondary flow. The ejector shroud was designed for compound/compressible choked operation of the ejector at cruise condition. Most of the jet mixing, inside the shroud, will occur near choked conditions. The thickness of the shroud was set by a trade between weight, take off performance, and cruise performance. The shroud inlet is designed to provide a continuously accelerating flow from the shroud secondary flow entrance to the nozzle lobe exit plane. The secondary inlet duct area is a minimum at the lobe exit plane. This assures that any choking of the secondary flow occurs at, or after the lobe exit plane. The axial placement of the secondary inlet entrance, with respect to the nozzle exit plane, is designed to assure the secondary flow follows the aggressive lobe lines, and results in optimum mixing with minimal flow losses. The shroud is attached to the engine nozzle lobes by ten separate pylons. Each pylon attaches the top of a lobe to the shroud inlet structure. The ten separate pylons provide minimal aerodynamic interference to the secondary flowfield. The mixer lobes break the nozzle exit plane up into smaller channels. These small channels result in some high frequency jet noise generation. The inner surface of the ejector shroud is treated with acoustical lining. The lining is designed to absorb the high frequency jet noise generated by the nozzle lobes. The shroud external boattail is designed to assure no flow separation occurs on the rear of the shroud.

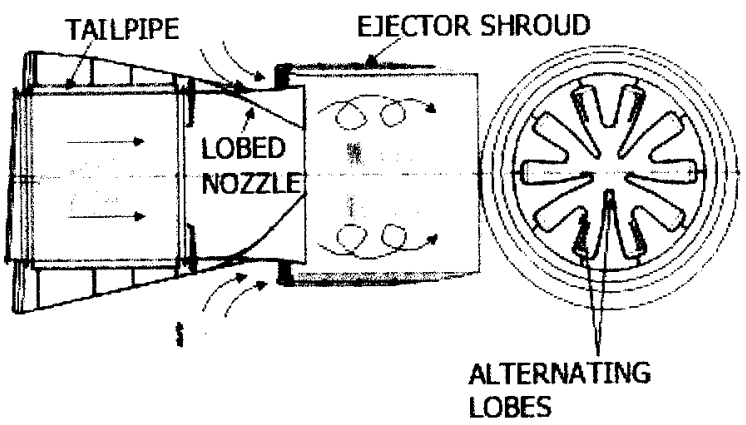

Figure 5 - ALMEC Suppressor System

This paper presents new information on thrust performance predictions, and thrust measurements of mixer/ejectors using the ALMEC system as the study configuration. Mixer/ejector performance procedures are presented which include classical control volume analyses, compound compressible flow theory, lobed nozzle loss correlations and state of the art computational fluid dynamic predictions. The mixer/ejector thrust predictions are compared to subscale wind tunnel test model data and actual aircraft flight test measurements. The results demonstrate that a properly designed mixer/ejector noise suppressor can increase effective engine bypass ratio and generate large thrust gains at takeoff conditions with little or no thrust loss at cruise conditions. The cruise performance obtained for such noise suppressor systems is shown to be a strong function of installation effects on the aircraft.

\section{Ejector Thrust Predictions}

\section{Control Volume Analyses}

Conservation principles and control volume analyses were used to generate closed form, ideal performance predictions for ejectors. Figure 6 presents a conventional ejector with the internal control volume used. Station 1 is at the exit of the primary nozzle. Station 2 is at the exit of the mixing duct. The flow is assumed uniform in the secondary and primary streams at station 1 , and in the mixed flow stream at station 2. The mixing duct is assumed to be a constant area duct. Wall friction in the mixing duct is neglected. The static pressure is assumed constant through both streams at station 1 and is below ambient pressure due to viscous entrainment effects of the primary flow. The static pressure is assumed constant, and at ambient pressure at station 2. All losses are neglected in the secondary flow between ambient air and station 1, therefore Bernoulli's equation of energy conservation is used between these two stations. Reference 9 shows that density, molecular weight and temperature effects do not play a major role in the physics of ejectors. An approximate Munk and Prim 


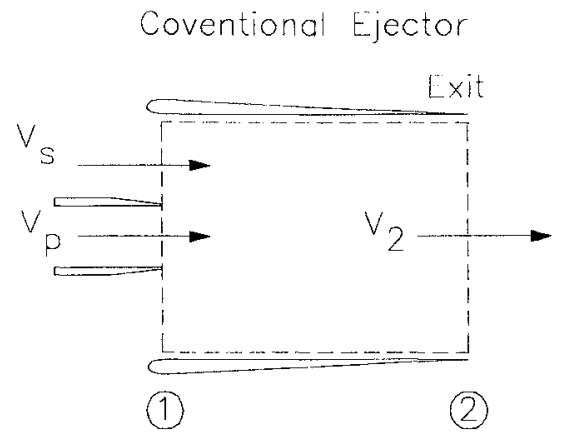

Figure 6 - Conventional Ejector with internal Control Volume

principle was used to collapse the data of ejectors with such variations into a single performance curve. Therefore, secondary and primary flow density are assumed to be the same for this analysis. Applying conservation of mass and momentum to the control volume in conjunction with Bernoulli's equation to the flow entering the control volume, one obtains the following equations for ejector pumping and thrust augmentation:

$$
\begin{gathered}
\frac{\dot{m}_{S}^{2}}{\dot{m}_{P}^{2}}\left(1+\left(\frac{A_{P}}{A_{S}}\right)^{2}\right)+4 \frac{\dot{m}_{S}}{\dot{m}_{P}}-2\left(\frac{A_{S}}{A_{P}}\right)=0, \\
\phi=\frac{\left(\frac{\dot{m}_{s}}{\dot{m}_{p}}+1\right)^{2}}{\left(\frac{A_{s}}{A_{p}}+1\right)\left[1-\left(\frac{\dot{m}_{s}^{2}}{\dot{m}_{p}^{2}}\right)\left(\frac{A_{p}^{2}}{A_{s}^{2}}\right)\right]^{\frac{1}{2}}} .
\end{gathered}
$$

Ideal pumping as presented in equation 1 is seen to be independent of pressure ratio, and only a function of the secondary to primary area ratio. Pumping is the ratio of the secondary flow rate over the primary flow rate of the nozzle. Figure 7 graphically presents ejector pumping as a function of area ratio, $\mathbf{A}_{\mathbf{s}} / \mathbf{A}_{\mathbf{p}}$. Ejector pumping is seen to continually increase as the secondary area of an ejector increases.

Thrust augmentation as presented in equation 2 is a non dimensional measure of the thrust increase associated with an ejector. It represents the ratio of the thrust of the ejector to the thrust of the baseline primary nozzle expanded to ambient pressure. A value of 1.0 means no thrust gain, or the ejector generates exactly the same thrust as the primary nozzle would if it was expanded to ambient pressure. The thrust augmentation is seen to be a function of both ejector pumping and ejector area ratio. Since pumping is a function of area

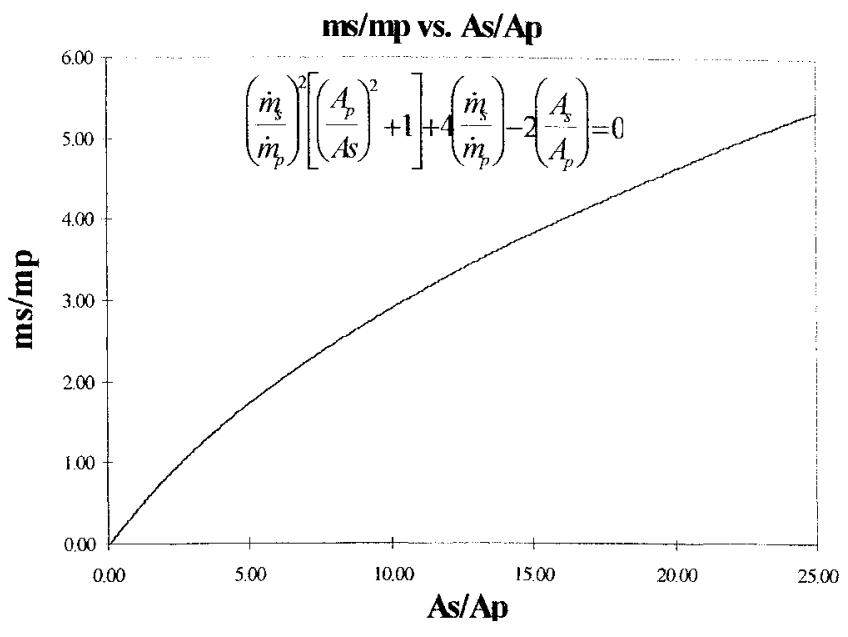

Figure 7 - Convention Ejector Pumping

ratio only, thrust augmentation values can be generated as a function of pumping only. This approach is consistent with Heiser's approach in Reference (1), and allows a comparison of ejector thrust performance with ideal augmentors. Figure 8 presents ejector thrust augmentation versus pumping. These results predict that an ejector always increases the static

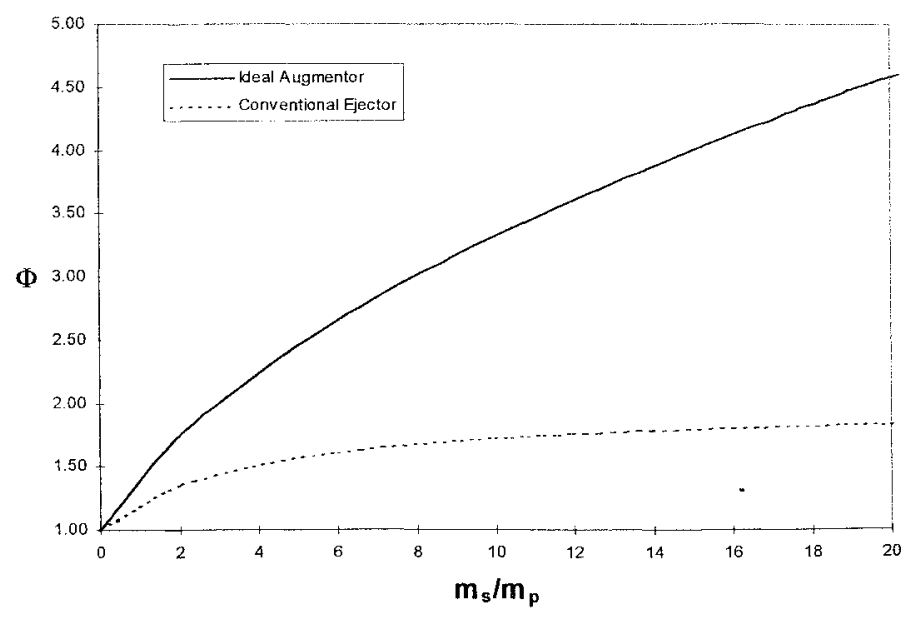

Figure 8 - Ejector Thrust Augmentation Variation

thrust of a nozzle. An ideal augmentor thrust curve is also presented for comparison purposes. The ejector thrust augmentation is seen to be close to an ideal augmentor at low pumping rates, to increase with pumping rate increase, and to asymptotically approach 2.0 at high pumping rates. The ejector thrust augmentation is always lower than the ideal augmentor curve, and diverges away from it at high pumping rates. The difference between these two curves is a result of the losses, and entropy rise, due to the viscous forces in the ejector energy transfer process. 
The following closed form, thrust augmentation equation can also be generated, from our control volume, for an ejector with forward flight:

$$
\Phi=\frac{\left(\frac{\dot{m}_{s}}{\dot{m}_{p}}+1\right)^{2}-\left(\frac{A_{s}}{A_{p}}+1\right)\left(\frac{\dot{m}_{s}}{\dot{m}_{p}}+1\right) \frac{V_{A}}{V_{P}}}{\left(\frac{A_{s}}{A_{p}}+1\right)\left[\left(1-\left(\frac{\dot{m}_{s}}{\dot{m}_{p}} \frac{A_{P}}{A_{s}}\right)^{2}+\left(\frac{V_{A}}{V_{P}}\right)^{2}\right)^{\frac{1}{2}}-\frac{V_{A}}{V_{P}}\right]} .
$$

Figure 9 graphically presents the results from equation 3 . Thrust augmentation, $\Phi$, is shown as a function of the ratio of airplane speed to the primary jet velocity (i.e. $\mathrm{Va} / \mathrm{Vp}$ ). Ejector thrust gains are seen to be a maximum at static operation, and to decrease asymptotically to zero as the ejector forward velocity approaches the primary flow velocity. Three secondary to primary ejector area ratios, As/Ap, are presented in Figure 9;1, 5, and 10. The results show that although static thrust gains of ejectors increase dramatically with area ratio increase, these gains rapidly drop off with forward flight. The drop off in thrust gain with flight speed is often called ram drag effects. As the airplane flight speed increases, the ingested secondary flow momentum increases. This

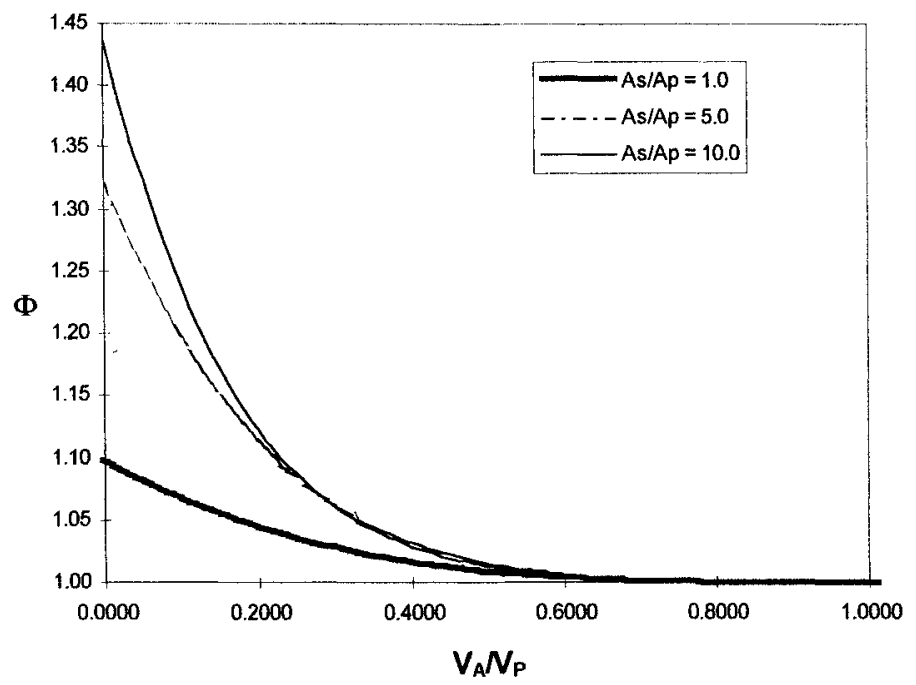

Figure 9 - Thrust Augmentation Variations

secondary flow momentum has to be subtracted from the thrust generated by the ejector, and thus results in lower ejector system thrust. The loss in ejector thrust augmentation physically shows up as less inlet lip suction. The ALMEC suppressor system has an area ratio As/Ap of 1 . As seen in Figure 9, control volume theory predicts an ideal thrust gain of approximately 10 percent for the ALMEC system at static conditions. This ideal thrust gain drops off dramatically with forward speed. These results assume uniform ejector flow, complete mixing and no lobed nozzle, shock or wall losses.

\section{Mixer/Ejector Loss Effects}

These ideal ejector control volume procedures were modified to include shroud losses, compressibility effects, lobed nozzle losses, and secondary flow losses associated with a mixer/ejector. The effect of shroud viscous forces on system thrust was estimated using boundary layer friction coefficients and drag relations presented in Reference 10. Any effect of shroud inlet flow separation was not included in the drag model. Actual airplane and jet velocities were used with full scale hardware dimensions to calculate the drag forces at different airplane speeds. Compressible flow ejector equations with compound flow choking procedures were used in the ejector mixing region as described in Reference 11. These analyses were combined with lobed nozzle loss correlations derived from References 12 and 13 . Figure 10 presents a

\section{PREDICTED EJECTOR THRUST GAINS}

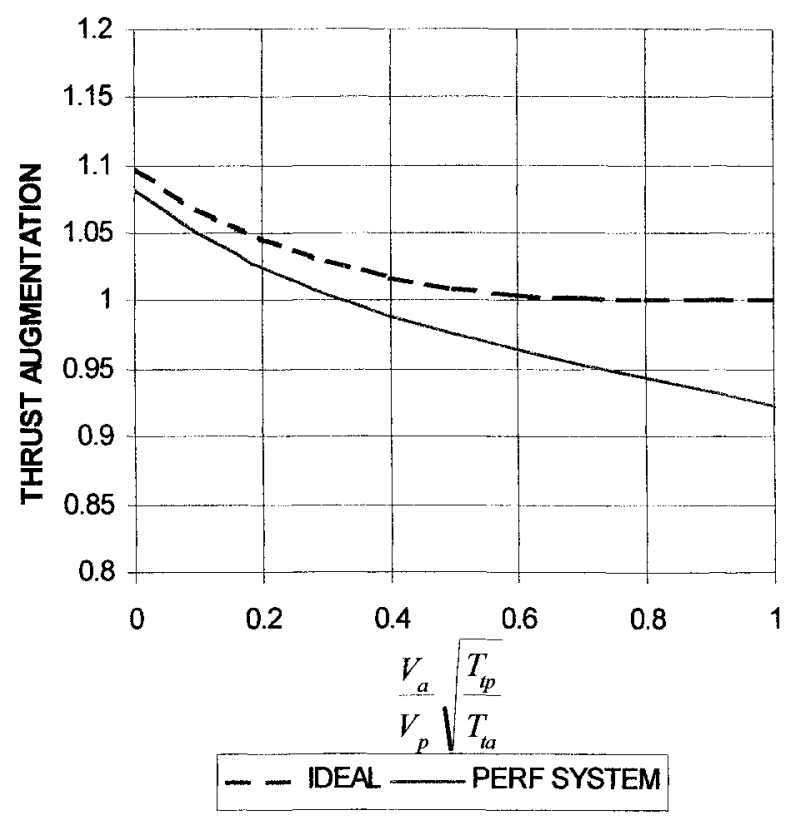

Figure 10 - Predicted Thrust For The ALMEC System

comparison of the predicted thrust of the ALMEC system both with, and without the losses. Thrust augmentation is presented as a function of a non-dimensional airplane speed ratio. This speed ratio term is a result of an approximate Munk and Prim principle (Reference 9) and is used to collapse ejector performance with different stream temperatures into a single performance curve. This result is extremely useful when comparing the predictions to wind tunnel test results. A $\frac{V_{a}}{V_{p}} \sqrt{\frac{T_{t p}}{T_{t a}}}$ of 0.62 corresponds approximately to cruise conditions for the Gulfstream aircraft. Figure 10 presents ejector performance predictions, with losses, over a range of aircraft flight velocities. At static conditions, the ideal thrust 
gain of the ALMEC suppressor is $10 \%$. The predicted value with losses is about $8 \%$. The ALMEC system is predicted to have approximately $3.5 \%$ loss in thrust at cruise flight velocities. These results do not include installation effects on the ALMEC mixer/ejector system.

\section{CFD Predictions}

A CFD study was conducted at cruise conditions to estimate the installation effects on the ALMEC system on the aircraft. The engine nacelle on the Gulfstream aircraft is pylon mounted on the fuselage. NASA's PAB3D Navier Stokes code was applied to the engine nacelle and the ALMEC ejector system at actual flight conditions. The NASA Langley Reynolds-averaged Navier Stokes (RANS) computational fluid dynamics (CFD) code PAB3D was used in conjunction with two-equation $k-\epsilon$ turbulence closure and a nonlinear algebraic Reynolds stress model to simulate ejector flow in this investigation. Over the years, the PAB3D code has been well tested and documented for the simulation of aeropropulsive flows involving separation, mixing, and other complicated phenomena (References 14 through 19). PAB3D solves the Reynolds-averaged Navier-Stokes equations in conservative form. Viscous models include coupled and uncoupled simplified Navier-Stokes and thin layer Navier-Stokes options (obtained by neglecting streamwise derivatives of the viscous terms). Roe's upwind scheme is used to evaluate the explicit part of the governing equations, and van Leer's scheme is used for the implicit part. Diffusion terms are centrally differenced, inviscid terms are upwind differenced, and two finite volume flux-splitting schemes are used to construct the convective flux terms. PAB3D is third-order accurate in space and first-order accurate in time. For numerical stability, various solution limiters can be used, including min-mod, van Albeda, and Spekreijse-Venkat. The code can utilize either a 2-factor or 3factor numerical scheme to solve the governing equations (Reference 17).

The nacelle and ejector/suppressor model used for computations was axisymmetric and the CFD simulation was conducted on a $5.625^{\circ}$ "wedge" shaped sector of the flowfield as shown in Figure 11. The three dimensional lobed nozzle was simulated as a round nozzle with the same area distribution. The three dimensional lobes are important for mixing and entraining flow at low airplane speeds. They were assumed to have little effect on installation losses at cruise conditions. At cruise conditions the secondary flow is rammed into the ejector as discussed previously. The ambient flow region surrounding the ejector extends approximately 15 primary nozzle diameters downstream of the ejector exit and 8 diameters normal to the jet axis. The computational grid consists of 35 blocks, defined by a total of 344182 points and 165136 hexahedral volume elements.

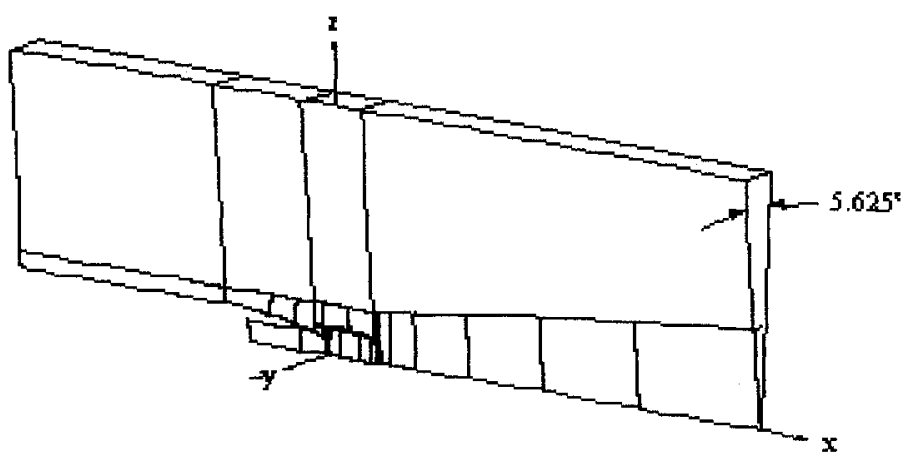

Figure 11 - Computational wedge

Stagnation conditions were applied to the left inflow face of the primary nozzle, and were chosen to match engine conditions for total temperature and total pressure. The ambient region surrounding the nozzle was defined by a subsonic inflow condition (specifying free stream temperature, pressure and Mach number) on the left face, a characteristic boundary condition on the top face, and a smart boundary condition on the right face that switched between constant pressure outflow (subsonic) and first order extrapolation (supersonic) depending on the local Mach number. All solid walls were treated as no-slip adiabatic surfaces. The bottom edge of the domain (i.e., the jet centerline) and axisymmetric symmetry planes of the domain were defined by inviscid walls. In order to initialize the turbulence transport equations and ensure the formation of a turbulent boundary layer in the nozzle, wall "trip" points were located near the beginning of the primary nozzle duct, on the external nozzle afterbody, and on the ejector shroud. At these points, $k$ was specified based on calculations involving the mean flow velocity and vorticity and a user specified intensity ratio. A corresponding value of $\epsilon$ was calculated based on the simplifying and reasonable assumption that the production of $k$ was equal to the dissipation of $k$ at the trip point.

CFD solutions were obtained by running PAB3D on a Silicon Graphics Octane workstation with a $195 \mathrm{MHz}$ MIPS-R 10000 CPU and $896 \mathrm{MB}$ of RAM. As part of the solution procedure, local time stepping was used with global CFL numbers ranging from 1 to 5 . To speed convergence and evaluate possible grid dependence, mesh sequencing evolved solutions through coarse ( $1 / 4$ resolution), medium ( $1 / 2$ resolution), and fine (full resolution) grids. In general, it took approximately 20,000 iterations and 30 hours of CPU time to obtain a fully converged solution. Convergence was judged by tracking integrated thrust efficiency until it settled to within $0.5 \%$ over at least 1000 iterations. The inline performance module of PAB3D was used in conjunction with an independent postprocessor to compute forces and moments by integrating pressure and momentum over a fixed control volume. 
Figure 12 compares the CFD predicted cruise performance with the control volume prediction system. The CFD thrust predictions are much higher than the control volume

PREDICTED EJECTOR THRUST GAINS

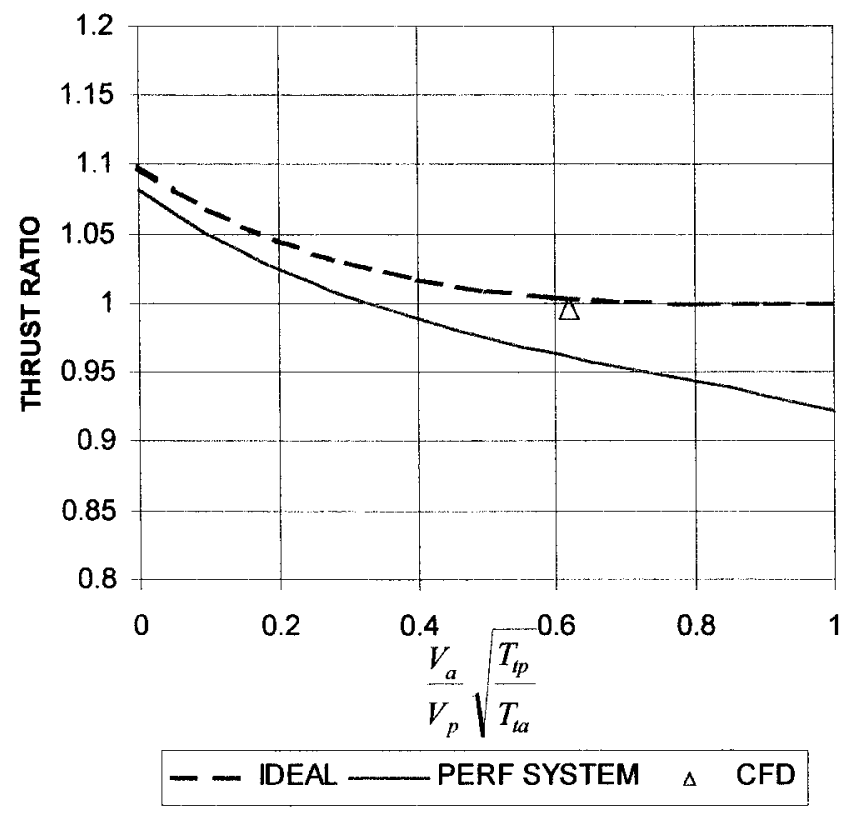

Figure 12 - CFD ALMEC Predictions

prediction results. The shroud contour is predicted to have good performance with less than a $1 \%$ loss in cruise thrust. This cruise performance loss does not include losses associated with the ALMEC lobed nozzle, and flow nonuniformities associated with real engine flow.

\section{Comparisons With Data}

\section{Scale Model Tests}

A scale model of the ALMEC system was tested at low nozzle pressure ratios at both Western New England College and Stage III Technologies research facility. The thrust values were measured using a load cell, force balance. The suppressor models were tested at various simulated flight speeds. Figure 13 shows a photograph of the test facility. The test facility is supplied by two sources of pressurized air. A primary stream is blown through the suppressor lobed nozzle. A venturi is located in the primary duct to measure flow rates. A separate fan is used to blow secondary flow over the ejector shroud simulating external flow effects. The secondary fan flow velocities can be varied from zero up to about sixty percent of the primary velocity. The ejector thrust is measured directly

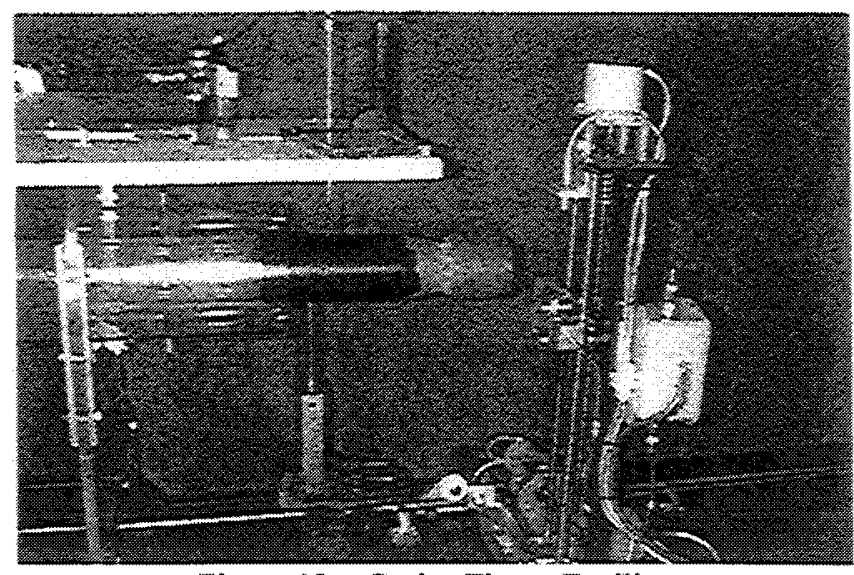

Figure 13-Cruise Thrust Facility

at all external speeds using an ejector shroud balance. A jet traverse system is shown in the photograph of the test facility (i.e. Figure 13). This traverse is computer controlled, and allows one to measure the complete exhaust jet profile. The same computerized traverse is used to measure the ejector shroud exit plane velocity field, and flow rates. The measured shroud flow rates and nozzle flow rates are used to generate pumping values for the suppressor. An ejector shroud balance was used to measure ejector thrust gains.

A comprehensive test of mixer ejector models operating at high pressure ratios, and simulated flight speeds was also conducted. The nozzle pressure ratio was varied from a little above one all the way up to five. The mixer/ejector thrust was measured using a force balance attached to the metric section of the model. Flow rates were measured using venturis. Both primary and secondary total conditions were recorded for each test. The measured pressures were used to calculate ideal thrust values for each test condition. Again, all the tests were conducted with cold flow and similarity principles presented in Reference 9 were used to extrapolate the cold flow data to hot flow predictions. Figure 14 presents a comparison of ALMEC performance predictions from control volume theory, CFD analyses, low speed wind tunnel tests, and the high pressure ratio model tests. Thrust augmentation (i.e. actual thrust of the ejector over the ideal thrust of a conical nozzle) is plotted versus the ratio of airplane velocity over the nozzle jet velocity times the square root of the temperature ratio. This similarity parameter allows the cold flow data and predictions to be used to approximate actual flight conditions as described in Reference 9. A similarity parameter (i.e. corrected velocity ratio) value of zero represents static performance. A ratio of about 0.62 corresponds to cruise airplane flight operation. The cross symbols represent the low speed test data. The dark square symbols represent measured, high pressure ratio thrust forces. This data includes shock losses and lobed nozzle losses. The model data agrees very well with the analytical 
PREDICTED EJECTOR THRUST GAINS

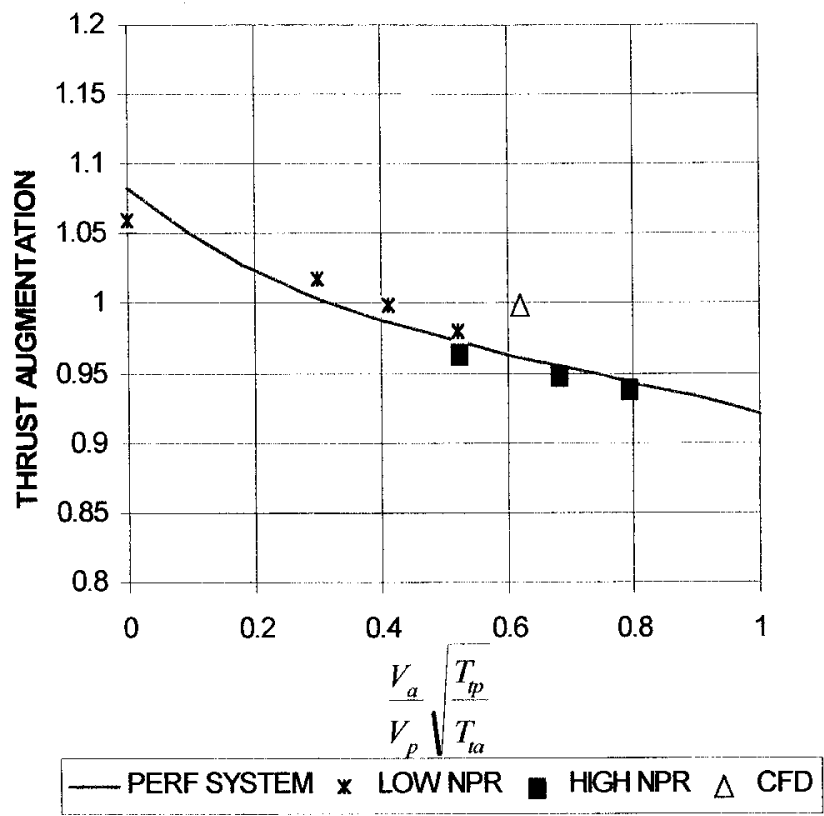

Figure 14 - Measured Thrust Values

predictions for thrust variation with aircraft flight speeds. The largest difference occurs at take off conditions, or zero flight speed. The ejector analyses predicts an $8 \%$ thrust increase. A $6 \%$ increase was measured with the scale model tests. This difference is probably due to inlet separation on the ejector shroud. The analyses assumes no separation at all flight speeds. Take off is the most critical operating point for inlet flow separation. The test data predicts a cruise thrust loss of about $4 \%$ for the ALMEC system. This value is quite close to the control volume prediction system. The CFD results, on the other hand, predict much higher cruise thrust performance than either the ejector prediction system, or the scale model test data. Both the mixer/ejector test data and the ejector performance system results do not include engine flow profile effects, thrust reverser losses, and other aircraft installation effects on ALMEC system performance.

\section{Engine Tests Results}

New engine static thrust tests of the Spey 511-8 jet engine were conducted both with, and without the ALMEC mixer/ejector suppressor installed. The tests were conducted using the static engine test stand at Brown Field, CA. Figure 15 is a photograph of the engine, engine nacelle, ALMEC system and the static test stand used. Thrust measurements were taken at various engine pressure ratios. Figure 16 presents the measured values. The baseline configuration is the flight nozzle. The measured engine thrust with the ALMEC system installed is seen to increase over the baseline

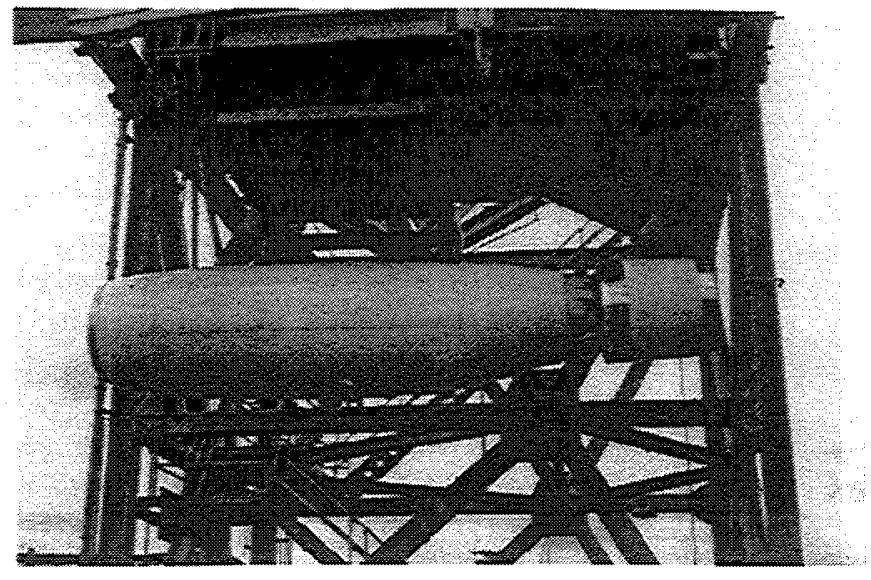

Figure 15 - Engine Static Test Stand

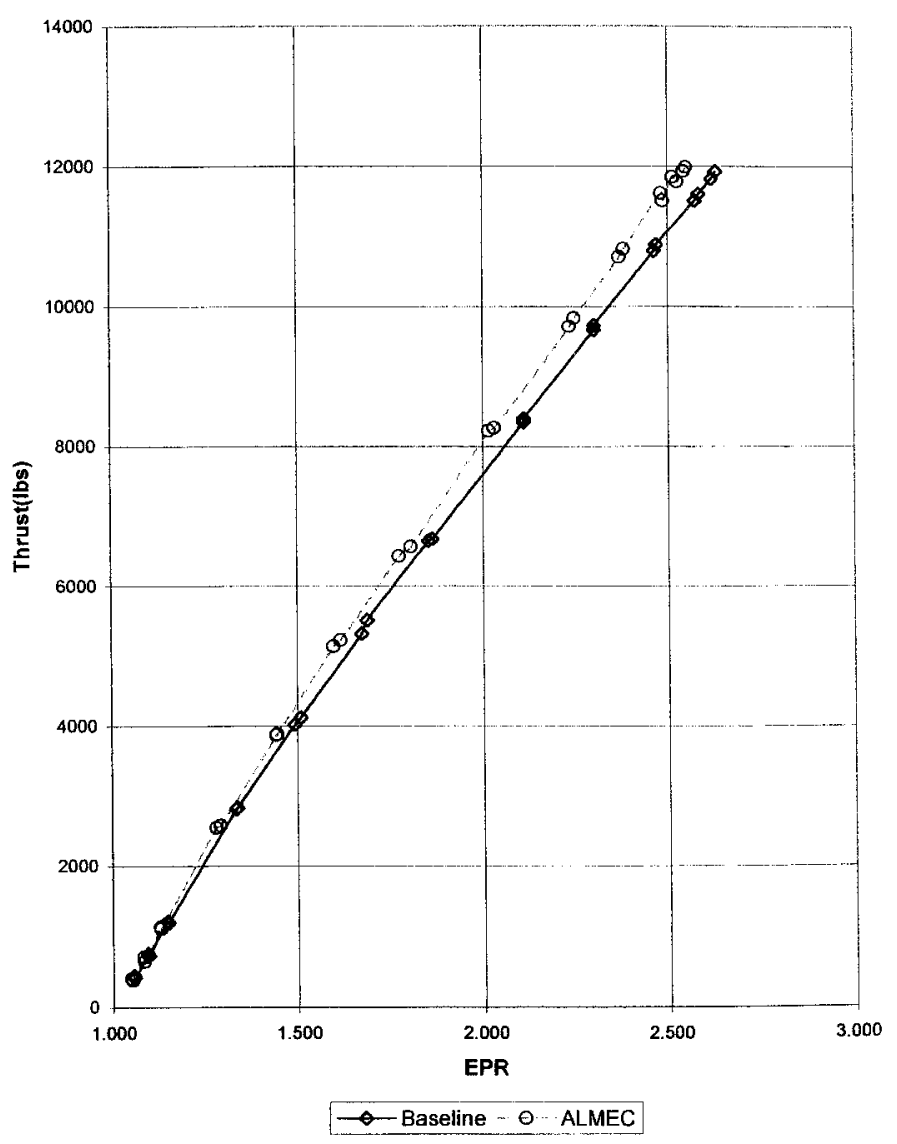

Figure 16 - Static Engine Thrust Measurements

nozzle thrust by about $5-7 \%$ over the entire range of engine operating conditions. These results were further confirmed in engine calibration tests at the Dallas Airmotive engine test facility.

Gulfstream GII flight performance data with the mixer/ejector system was also measured. Figure 17 is a photograph of the 
ALMEC suppressor prototype installed on the Gulfstream aircraft. The ALMEC hardware was made of titanium. It replaced the baseline flight nozzle and reverser hardware, and generated no aircraft weight increase. Figure 18 presents a comparison of all the predicted and measured thrust augmentation values for the ALMEC suppressor system. The

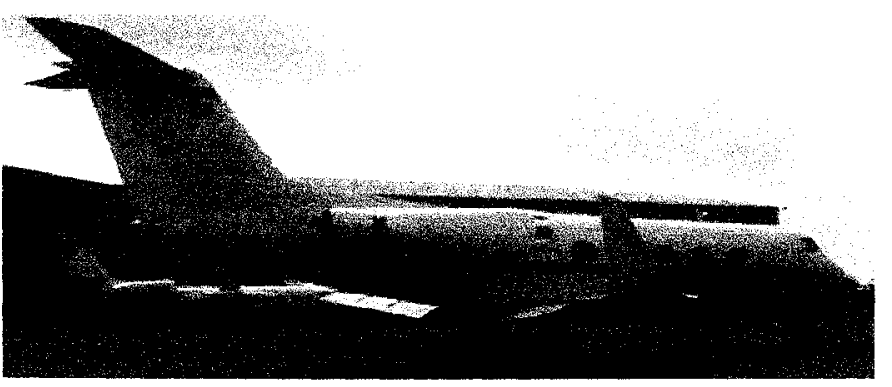

Figure 17 - ALMEC System Installed On The Aircraft

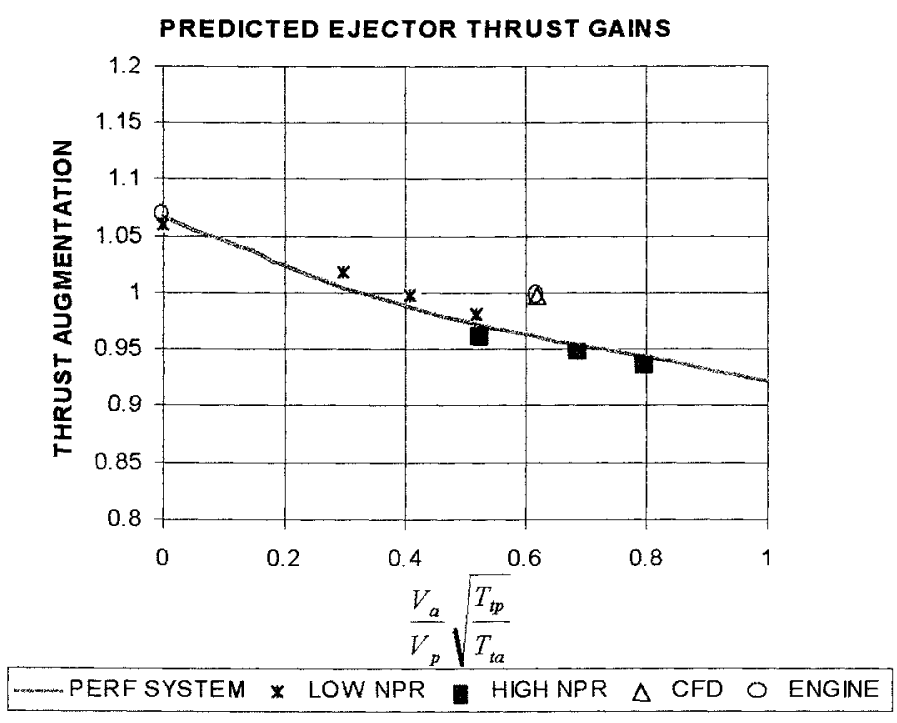

Figure 18 - ALMEC Thrust Values

engine results presented are from the static stand tests of the Spey 511-8 engine, and flight tests of the Gulfstream aircraft. The flight results indicate no cruise thrust loss, and verify the CFD predictions. A review of the CFD predicted flowfield indicates that this lower cruise thrust loss is a result of installation effects. At cruise condition the ejector is partially ingesting low energy, afterbody boundary layer flow. This reduces the boundary layer build up on the afterbody and reduces afterbody drag. The same low energy, boundary layer flow ingestion by the ejector also results in better ejector thrust performance. The lower energy level of the ingested secondary flow, when compared to the engine flow, results in lower ram drag and therefore more thrust augmentation for the ejector. Figure 19 presents the CFD predicted flowfields over the engine nacelle with both the flight nozzle and the
ALMEC ejector. Examining the two color charts in Figure 19 it is seen that the average predicted Mach number of the flow entering the ejector at cruise conditions is about 0.45 . This is well below the cruise Mach number of 0.8 , and is a result of the boundary layer over the nacelle. The red triangle in Figure 18 shows the CFD predictions assuming the secondary flow is ingested at cruise Mach number. A more realistic secondary flow Mach number of 0.45 corresponds to a corrected velocity ratio of 0.35 instead of the plotted value of 0.62 . It is seen that both the flight test results and the CFD prediction, if corrected for installation boundary layer effects (i.e. plotted at 0.35 ), would agree very well with the low speed data and the control volume predictions.

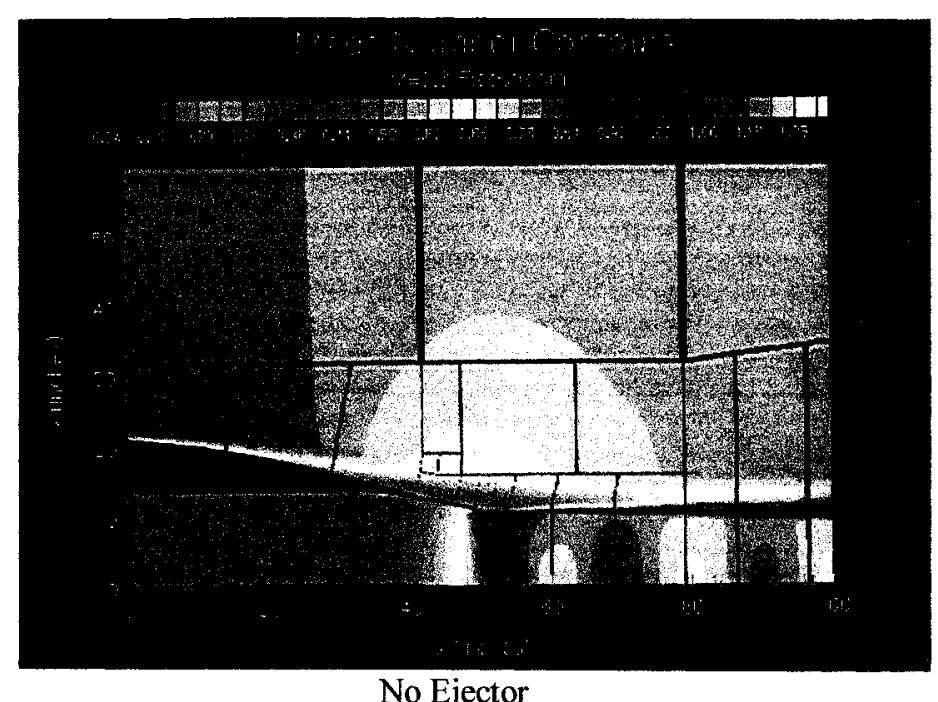

No Ejector

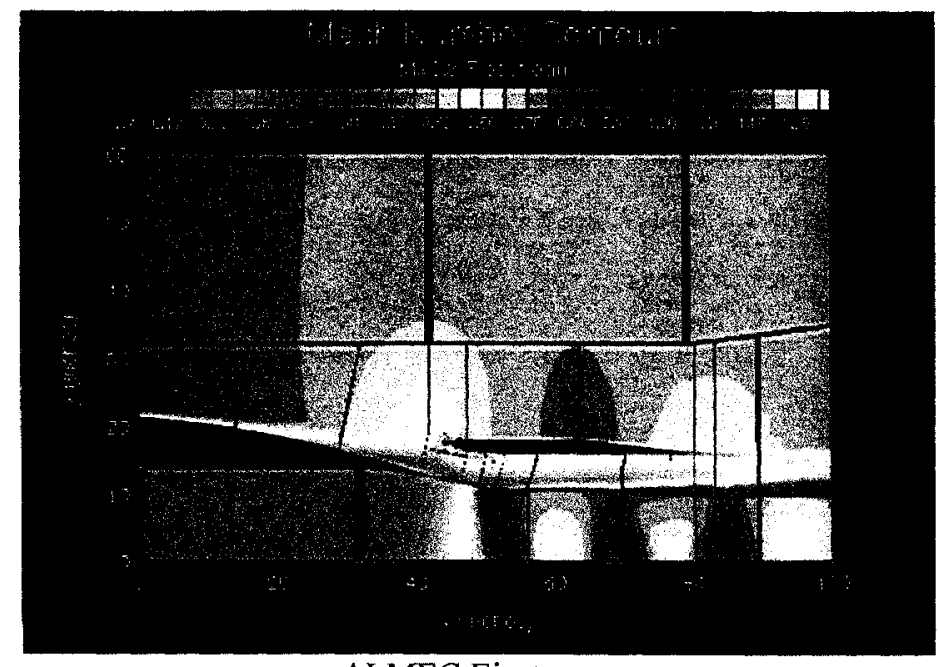

ALMEC Ejector

Figure 19-CFD Flowfield Predictions 


\section{Conclusions}

Mixer/ejector exhaust systems provide a simple means of reducing the jet noise on older aircraft. Properly designed mixer/ejectors can increase engine bypass ratio while generating an increase in static thrust. The thrust increase is a result of ejector inlet suction forces generated by the secondary flow accelerating around the inlet contour. The same inlet contour also directs the secondary flow into the ejector for low loss mixing. Therefore, the design of the ejector shroud inlet is critical to the performance of a mixer/ejector system. As the airplane speed increases, the secondary flow accelerates less around the inlet lip resulting in lower lip suction forces, and therefore lower thrust augmentation. This loss in thrust is a result of inlet ram drag.

Control volume thrust predictions compare well to wind tunnel test data and jet engine test measurements with mixer/ejector exhaust systems. Aircraft test results demonstrate that a properly designed mixer/ejector can generate large thrust gains at takeoff conditions with small thrust losses at cruise conditions. The cruise performance of mixer/ejectors is strongly dependent on installation effects. The low flight thrust loss of the ALMEC suppressor at cruise is a result of low ejector ram drag caused by the ejector ingesting large nacelle boundary layers. The lower velocity boundary layer flow entering the ejector inlet reduces the ram drag at cruise flight conditions.

\section{References}

1. Heiser, William H., Thrust Augmentation, ASME Paper \#66-GT-116, 1966.

2. Presz, W., Morin B., and Gousy, R., Forced Mixer Lobes in Ejector Designs, Paper No. 86-1614, AIAA 22nd Joint Propulsion Conference, June, 1986.

3. Presz, W., Morin, B., and Blinn, R., Short Efficient Ejector Systems, Paper No. 87-1837, AIAA 23rd Joint Propulsion Conference, June, 1987.

4. Skebe, S., McCormick, D., and Presz, W., Parameter Effects on Mixer-Ejector Pumping Performance, Paper No. 88-7018, AIAA 26th Aerospace Science Meeting, January, 1988.

5. Tillman, G., and Presz, W., Thrust Characteristics of a Supersonic Mixer Ejector, Paper No. 93-4345, 15th AIAA Aeroacoustical Conference, October, 1993.

6. Presz, W., Reynolds, G. and McMormick, D., Thrust Augmentation Using Mixer / Ejector / Diffuser Systems, Paper No. 94-0020, AIAA 32 ${ }^{\text {nd }}$ Aerospace Science Meeting, January 1994.
7. Presz, W., Mixer/Ejector Noise Suppressors, Paper No. 91-2243, AIAA 27th Joint Propulsion Conference, June, 1991.

8. Presz, W. and Reynolds, G., Alternating Lobed Mixer/Ejector Concept Suppressor, ALMEC Suppressor, United States Patent 5,884,472, March, 1999

9. Presz, W., and Greitzer, E., A Useful Similarity Principle for Jet Engine Exhaust System Performance, Paper No. 88-3001, AIAA 24th Joint Propulsion Conference, July 1988.

10. Hoerner, S.F., Fluid Dynamic Drag, published by author, Library of Congress No. 64,19666, 1965.

11. Bernstein, A., Heiser, W. and Hevenor, C., Compound Compressible Nozzle Flow, Paper No. 66-663, AIAA $2^{\text {nd }}$ Propulsion Joint Specialist Conference, June, 1966.

12. Presz, W and Zecca J., Application of Multi-Stage Hyper-Mixers to Combustors, Final Report, FTS/NASA SBIR Contract NAS3-98069, August, 1998.

13. Kozlowski, H. and Larkin, M., Energy Efficient Engine Exhaust Mixer Model Technology Report, NASA Report No. NASA-CR-165459, June, 1981.

14. Pao, S.P., and Abdol-Hamid, K.S., Numerical Simulation of Jet Aerodynamics Using a Three Dimensional Navier Stokes Method (PAB3D), NASA TP-3596, September 1996.

15. Abdol-Hamid, K.S. Implementation of Algebraic Stress Models in a General 3-D Navier-Stokes Method (PAB3D), NASA CR-4702, December 1995.

16. Abdol-Hamid, K.S., Lakshmanan, B., and Carlson, J.R., Application of the Navier-Stokes Code PAB3D with $k$ - $\in$ Turbulence Models to Attached and Separated Flows, NASA TP-3480, January 1995.

17. Carlson, J.R., High Reynolds Number Analysis of Flat Plate and Separated Afterbody Flow Using Non-Linear Turbulence Models, AIAA 96-2544, July 1996.

18. Hunter, C.A., Experimental, Theoretical, and Computational Investigation of Separated Nozzle Flows, AIAA 98-3107, July 1998.

19. Hunter, C.A. and Deere, K.A., Computational Simulation of Fluidic Counterflow Thrust Vectoring, AIAA 99-2669, June 1999. 